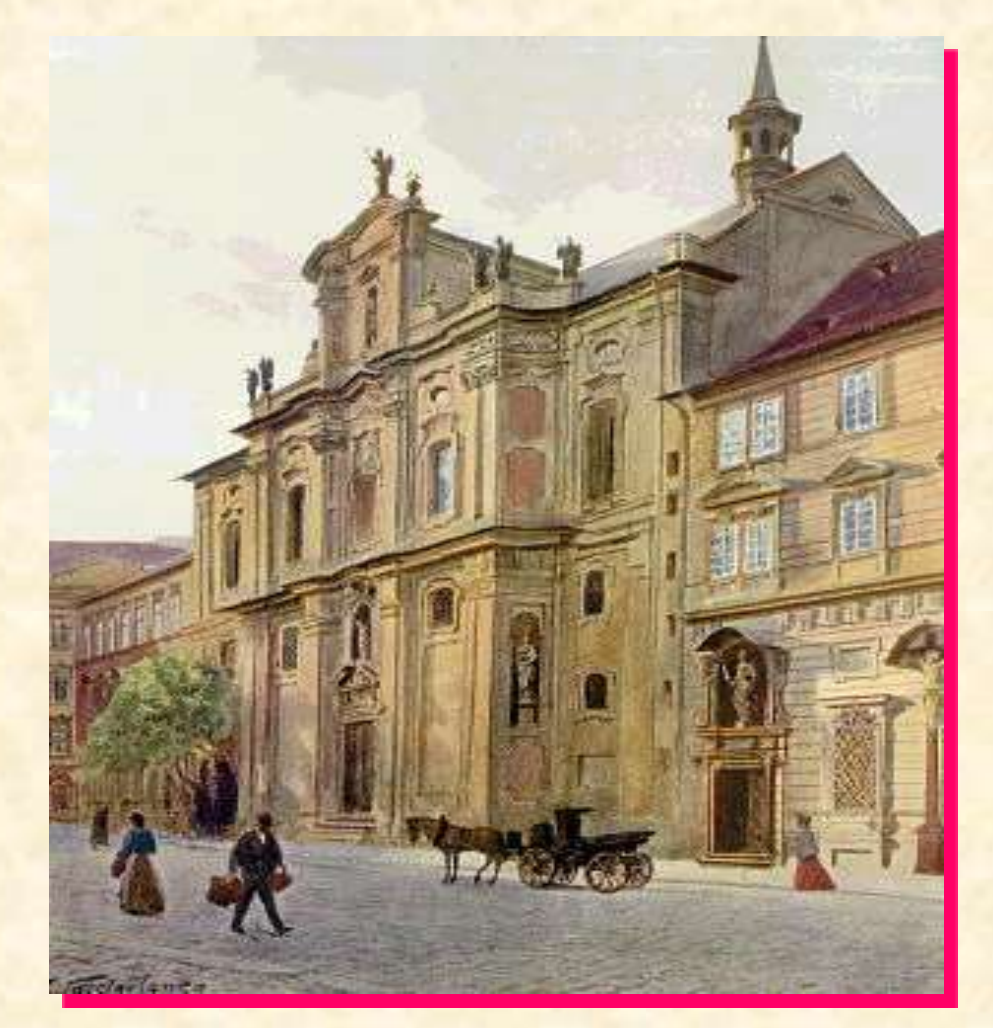

\title{
The Role of Steroid Hormones in the Development of Postpartum Depression
}

\section{Michaela Dušková1, Antonín Pařízek², Michaela Mikešová2, Roman Jirák ${ }^{3}$,} Martin Hill1,2, Karolína Adamcová2 and Luboslav Stárka ${ }^{1}$

\footnotetext{
2 Department of Obstetrics and Gynecology, First Faculty of Medicine, Charles University and General Teaching Hospital, Prague, CZ ${ }^{3}$ Department of Psychiatry, First Faculty of Medicine, Charles University and General Teaching Hospital, Prague, CZ
}

\section{INTRODUCTION:}

Postpartum depression affects 10-15\% women after childbirth. Despite several hypotheses, there is no currently generally accepted theory about the causes and mechanisms of postpartum mental disorders. It is very likely that this process is associated with sudden changes in the production of hormones affecting the nervous system of the mother and, on the other hand, with the ability of receptor systems to adapt to these changes.

\section{METHODS:}

We observed changes in steroidogenesis in the period around spontaneous childbirth. The first sampling of maternal blood was performed 4 weeks prior to term. The second sampling was performed after the onset of uterine contractions (the beginning of spontaneous labour). The third sampling was performed during the third stage of labour (immediately after childbirth). Additionally, we collected mixed umbilical cord blood. The almost complete steroid metabolome was analysed by means of gas chromatography - mass spectrometry, or using RIA for some steroids. Mental changes in women in the peripartum period were observed using the Hamilton Depression Rating Scale.

\section{RESULTS:}

We monitored changes in steroid levels in maternal blood during the first three sample collections (i.e. four weeks prior to childbirth, after the onset of uterine contractions (the beginning of labour), and in the 3rd stage of labour (immediately after childbirth)) and in mixed umbilical cord blood. Some of the changes in steroid hormone levels found were shown to be significant of the development of depression in the postpartum period.

Four weeks prior to childbirth, we found already the changes in androgens levels correlating with postpartum mood disorders (Table 1). In contrast, steroid hormone levels at the onset of uterine contractions there was no changes related to postpartum mood disorders. Overall, however, the strongest changes was found in samples collected after childbirth. Both testosterone, most likely of maternal origin (Table 2), and estrogens from the fetal compartment (Table 3 ) played the main role. Testosterone from umbilical cord blood did not change.

\begin{tabular}{|c|c|c|c|}
\hline Variable & Without depression & Mild depression & Moderate depression \\
\hline Age & $33(31,37)$ & $31.5(29.5,32.8)$ & $33(31,34)$ \\
\hline Androstenedione & $5.28(3.21,6.94)$ & $7.22(5.74,9.14)^{*}$ & $8.1(6.81,13.8)^{*}$ \\
\hline $5 \beta$-Dihydroprogesterone & $1.09(0.91,1.8)$ & $0.817(0.62,1.08)$ & $1.29(0.979,1.65)^{*}$ \\
\hline Androstene & $0.383(0.21,0.526)$ & $0.432(0.363,0.537)$ & $0.495(0.378,0.954)^{*}$ \\
\hline $5 \alpha$-Androstane- $3 \alpha, 17 \beta$-diol & $0.0352(0.026,0.0727)$ & $0.0345(0.0191,0.0688)$ & $0.112(0.0772,0.236)^{*}$ \\
\hline 17-Hydroxypregnenolone & $0.68(0.34,1.49)$ & $1.45(0.845,2.21)^{*}$ & $1.13(0.42,2.34)^{*}$ \\
\hline Testosterone & $3.69(2.83,4.66)$ & $4.01(3.46,5.03)$ & $4.68(4.4,5.76)^{*}$ \\
\hline
\end{tabular}

\begin{tabular}{|c|c|c|c|}
\hline Variable & Mild depression & Moderate depression & Without depression \\
\hline Age & $33.5(30.3,36.5)$ & $31(29,32)$ & $33(31,34)$ \\
\hline Androstenedione & $6.61(4.21,10.1)$ & $8.92(3.22,11.1)^{*}$ & $13.9(8.45,15.1)^{*}$ \\
\hline Allopregnanolone & $9.59(5.7,13.7)$ & $6.02(4.01,8.63)$ & $11.5(6.81,20.6)^{*}$ \\
\hline Androsterone & $0.426(0.37,0.671)$ & $0.405(0.318,0.691)$ & $1.14(0.638,1.39)^{*}$ \\
\hline $5 \alpha$-Androstane-3 $3,17 \beta$-diol & $0.464(0.0321,0.078)$ & $0.0392(0.031,0.138)$ & $0.104(0.0636,0.124)^{*}$ \\
\hline $5 \alpha$-Androstene- $3 \beta, 7 \beta, 17 \beta$-triol & $0.429(0.0329,0.0797)$ & $0.0479(0.0409,0.0663)$ & $0.0802(0.068,0.159)^{*}$ \\
\hline Estradiol & $9.89(6.64,13.3)$ & $8.54(1.15,14)$ & $14.7(12.4,17.5)^{*}$ \\
\hline Estriol & $90.5(50.3,163)$ & $80.6(13.3,98.9)$ & $161(67.6,191)^{*}$ \\
\hline Testosterone & $4.07(2.39,5.95)$ & $4.16(3.02,5.3)$ & $7.45(5.2,7.99)^{*}$ \\
\hline
\end{tabular}

Table 3. Significant changes in steroid levels related to postpartum mental disorders in mixed umbilical cord blood.

\begin{tabular}{|c|c|c|c|}
\hline Variable & Without depression & Mild depression & Moderate depression \\
\hline Age & $33(29.5,36.5)$ & $30(28.8,31.3)$ & $32(30.5,33)$ \\
\hline Estradiol & $9.32(7.45,18.7)$ & $19.8(16.7,24.8)^{*}$ & $19(11.3,24)^{*}$ \\
\hline Estron & $63.4(37,95.7)$ & $62(40.2,152)^{*}$ & $84.6(58.4,105)^{*}$ \\
\hline Estriol & $133(79.8,228)$ & $270(85.2,448)^{*}$ & $297(173,314)^{*}$ \\
\hline 16a-Hydroxy-progesterone & $77.7(58.1,92.9)$ & $147(128,221)^{*}$ & $175(126,205)^{*}$ \\
\hline
\end{tabular}

\section{CONCLUSION:}

These results suggest that changes in both maternal and fetal steroidogenesis are involved in the development of mental changes in the postpartum period. Descriptions of changes in steroidogenesis in relation to postpartum depression could help clarify the causes of this disease, and changes in some steroid hormones are a promising marker of mental changes in the postpartum period. 